\title{
The application of AHP in performance evaluation of ideological and political education in colleges and universities
}

\author{
Zhang Jinqiu ${ }^{1,}$, , Zhang XuDong ${ }^{2}$ \\ 1,2 Sichuan University of Science and Engineering, Zigong 643000,China \\ a498808258@qq.com
}

Keywords: Analytic hierarchy process; ideological and political education; performance evaluation

\begin{abstract}
The performance evaluation of ideological and political education in colleges and universities has the uncertain factors, vague scope definition, and the simple evaluation instruments, it's hard to evaluate the performance evaluation of ideological and political education in colleges and universities and get good results. Analytic hierarchy process is a effective methods which is aimed at the results that is difficult to accurately measure .The application of analysis hierarchy process in the evaluation of ideological and political education in colleges and universities, by analyzing the problems of performance influencing factors and the essence, together the analytic hierarchy process and fuzzy comprehensive evaluation. What's more, using the quantitative information to get the reasonable evaluation is a particularly effective way, and improved the evaluation of science and rationality.
\end{abstract}

\section{Introduction}

Starting from 1960 to today, under the condition of China's development of science and technology, China's higher education has got the great achievement, and entered the stage of development of mass. School became a legal entity. Meanwhile, the world has undergone rapid change in higher education. Not entirely only benefits, higher education with its development produced a number of issues. Such as the problems of a sharp rise in the cost of education at the university, and the college students' growing number and so on. These have become a social spot for people, and the widespread media attention. In the development of mass higher education, although it raises the rate of college students, at the same time it was caused by low rates of college graduates ' employment, quality problems. Under these conditions, it's beneficial to analyze the performance evaluation of ideological and political education in colleges and universities to improve educational quality and reduce the unemployment rate, and make the higher education development in our country.

\section{The basic principle and reasonable criteria of performance evaluation of colleges and universities}

Performance evaluation of higher education in China has gone through a long history, the evaluation which from qualitative to the combination of quantitative and qualitative, from single to multi-tool set. Many scholars began its exploration and research. Many scholars began its exploration and research. For the performance evaluation of the ideological education in colleges and universities, first of all, in accordance with its basic principles and scientific standards, and then applying a reasonable evaluation method, and finally performance value assessment system of College ideological education process. Different scholars has different methods to study this case, while in this paper the authors state that the political and ideological education in universities' performance through using of scientific and rational approach to University managers overall judgment of decision makers of the value of work. Performance evaluation of ideological education in colleges and universities must be based on scientific method, reasonable evaluation principles and standards. Its standard can be listed as follows. Firstly is subjective, secondly is operative and thirdly is scientific. We also cannot ignore its standards, the first is political criteria, the second is the standard thought and the third is realistic standards. Political criteria is designed to keep consistency between the interests of pedagogue and by the pedagogue and selves. Standards aimed at making pedagogue's right thoughts by some proper ways for educators and make them get it. 


\section{Recent research on performance evaluation of ideological and political education in colleges and universities}

Performance evaluation of higher education in China has gone through a long history, the evaluation which from qualitative to the combination of quantitative and qualitative, from single to multi-tool set, so that so many scholars explore this issue. Such as Professor Lee used Markov chain is homogeneous for time and ways of efficiency to make up for the lack of qualitative assessment, because it can be more accurate to assess the characteristics, and describes the qualitative. Zhao Huanping using neural networks to make up the fuzzy systems, use the neural network self-learning ability and logical reasoning skills to establish a performance evaluation of ideological and political education in colleges and universities based on fuzzy neural network system. In order to provide the truly basis of high university, Hu Xiongying developed on the basis of performance evaluation of predecessors, successfully summarized a method for evaluating the performance of colleges and universities. Its fundamental purpose is to achieve a comprehensive assessment of university teachers ' performance. Li Daoguo and several relevant experts believe that the current assets in colleges and universities is lack of effective management system, they proposed mode of University assets management performance evaluation based on radar analysis. Zhang Xiaolin believes that by the method of factor analysis to performance evaluation of higher ideological and political education.Shen Hong used a flat cross created a new scorecard five-membered structural performance evaluation system of College ideological and political education, he used a cleverly calculated improved fuzzy AHP evaluation of rationality.

\section{The scope of evaluation and the fuzziness of content of ideological and political education in colleges and universities}

Performance scope and content of the ideological and political education in colleges and universities of our country of uncertainty fuzziness brings a certain degree of resistance to the researchers when they do the evaluation. Most of the cases is mainly reflected in the following five-point, the first is the ambiguity of evaluation of the content, the second is the vagueness of inputs and outputs, and the third is the evaluation of the uncertainty range, the forth is the uncertain standards of evaluation of university students' ideological and ethical qualities, the fifth is the high performance lagged effect of ideological and political education. From this five points can be resulted out in this evaluation of ideological and political education of higher performance, some people are more visual attention and evaluation of the dominant, with direct effect in the near future. While at the same time ignoring long-term, hidden, indirect effects, input of ideological and political education of higher performance including implicit and explicit inputs. Explicit input containing the money, time, manpower, so it's easy to be evaluated. Hidden inputs include early access to educational outcomes and educational aspects of intangible assets. It is more difficult to assess ,as we all know, the goal of college education is to train the students to develop the excellent human, that is to say ,to teach students political and ideological. But cultivating the students' political and ideological is a system project, it consists of teaching management and teaching, extra-curricular activities and complementary role of the family.

\section{Current evaluation methods of ideological and political education and its drawbacks}

Usually the researchers divided it into two main parts when they study on performance evaluation method of University ideological and political education, the first is a qualitative evaluation, the second is a quantitative assessment. To the first qualitative evaluation methods, it can be divided into system analysis and comparative analysis. System analyze mainly on performance evaluation and ideological and political education in colleges and universities. But comparative analysis is an analysis of the relevant elements of comparison and to confirm that the evolution and trend of things. Its drawback is the lack of ideological and political education evaluation of the performance of a comprehensive assessment of the system. For the second quantitative evaluation methods, first of all, it emphasizes a word of quantity, it is mainly included targeted law, effectiveness evaluation, 
equal-weighted method. We learned in high school to make the quantity a qualitative leap from the quantitative change accumulation, with less number of eventual change process.

Based on the analytic hierarchy process to performance evaluation of ideological and political education in colleges and universities

a. The foundation of performance system of ideological and political education in colleges and universities.

This paper studied on the research results of most of the scholars at home and abroad, through a combination of practical reality in China to establish a teaching, scientific research, social and financial performance of ideological and political education in colleges and universities in four evaluation level indicators. On the one hand, in the process of continuous scale in universities, under the condition of shortage of government funding, depends on loans from financial institutions, colleges and universities increased the amount of credit risk. After established the first level indicators, China began to set up a performance evaluation of ideological and political education in colleges and universities library, and then dividing by indicator library to develop principles, such as combining financial and non-financial indicators, comparability with the combination of operational principles.

\section{b. The indicators determining the weight of AHP}

On the basis of the analytic hierarchy process ,this article asked the performance evaluation of University's ideological and political education from experts has undertaken a number of consultations and on the ideological and political education performance indicators surveys and the use of the software in the form of performance indicators of balance of ideological and political education in colleges and universities.

\section{c. On the fuzzy comprehensive evaluation}

Use AHP method to determine the index number and combined with fuzzy comprehensive evaluation and college data can be associated with specific analytical performance evaluation of ideological and political education in colleges and universities. We can use reviews, such as excellent, good, use V1 instead by excellent, V2 instead by good, V3 instead by middle, V4 instead by bad. After all things be ready include comments, we can research performance of relevant experts on ideological and political education in colleges and universities ideological and performance assessment scores.

The basic process combining analytic hierarchy process on performance evaluation of ideological and political education in colleges and universities

This thesis introduced several steps: first, according to the purposes and functions of ideological and political education system and then analysis and confirms evaluation index system .The second step, under each evaluation to get the degrees according to each index. Thirdly, the integrated assessment followed by calculating each indicator system and comprehensive evaluation of values of rating value. The fourth step is using the final evaluation of the maximum membership grade principle system level.

\section{a. Confirm performance targets set}

Like these: $U=\{U 1, U 2, U 3, U 4, U 5\}, U 1=\{U 11, U 12, U 13\}, U 2=\{U 21, U 22, U 23, U 24\}$ $\mathrm{U} 3=\{\mathrm{U} 31, \mathrm{U} 32, \mathrm{U} 33\}, \mathrm{U} 4=\{\mathrm{U} 41, \mathrm{U} 42\}, \mathrm{U} 5=\{\mathrm{U} 51, \mathrm{U} 52, \mathrm{U} 53\}$

b. Confirm the set of target language.

Confirm comment rating $\mathrm{V}=\{\mathrm{V} 1$, V2, V3....V $\mathrm{m}\}=\{$ excellent, good, middle, bad $\}$

\section{c. Confirm the evaluation index weight by AHP}

Weighting refers to an indicator in the evaluation index system of overall importance of variables.

\section{d. Single-factor evaluation matrix.}

Evaluation index of actual values to the original non-gang, identifying evaluation indicators values 
are, in general, poor level.

\section{Summary}

Necessary part of the process of ideological and political education is the correct evaluation of the performance of ideological and political education of colleges and universities, this paper attempts using the AHP to solve the uncertainty and ambiguity successfully in performance evaluation of University's ideological and political education, and make the ideological and political education in colleges and universities became more convincing and scientific.

\section{References}

[1] Hui-li Yao,Chun-guang Lian,Jing-xian BAI. Application of Analytic Hierarchy Process (AHP) in shipyard project investment Risk Recognition[J]. Canadian Social Science,2009,55:

[2] Chunlan Qiu,Yonglin Xiao. The Application of AHP in Electric Resource Evaluation.[J]. Computer and Information Science,2008,1:.

[3] Chunlan Qiu,Yonglin Xiao. The Application of AHP in Electric Resource Evaluation[J]. Computer and Information Science,2009,12:.

[4] JenniferShang,LuisVargas. New Concepts and Applications of AHP in the Internet Era[J]. J. Multi - Crit. Decis. Anal.,2012,191-2:.

[5] Davood Samari,Hossein Azadi,Kiumars Zarafshani,Gholamhossein Hosseininia,Frank Witlox. Determining appropriate forestry extension model: Application of AHP in the Zagros area, Iran[J]. Forest Policy and Economics,2011,15:. 